\title{
Clinical Characteristics of 46,XX Males with Congenital Adrenal Hyperplasia
}

\author{
(1) Şenay Savaş-Erdeve1, (1) Zehra Aycan², (1) Semra Çetinkaya ${ }^{1}$, (1) Ayşe Pınar Öztürk³, (1) Firdevs Baş3 , (1) Şükran Poyrazoğlu³, \\ (1) Feyza Darendeliler33, (1) Elif Özsu², (1) Zeynep Şıklar2, (1) Meliha Demiral4, (1) Edip Unal4, (1) Mehmet Nuri Özbek4 , (1) Fatih Gürbüz5, \\ (1) Bilgin Yüksel5, (1) Olcay Evliyaoğlu6, (1) Nesibe Akyürek7, (1) Merih Berberoğlu² \\ 1 University of Health Sciences Turkey, Dr. Sami Ulus Obstetrics and Gynecology, Children's Health and Disease Training and Research Hospital, \\ Clinic of Pediatric Endocrinology, Ankara, Turkey \\ ${ }^{2}$ Ankara University Faculty of Medicine, Department of Pediatric Endocrinology, Ankara, Turkey \\ 3 istanbul University Faculty of Medicine, Department of Pediatric Endocrinology, istanbul, Turkey \\ 4 University of Health Sciences Turkey, Diyarbakır Gazi Yaşargil Training and Research Hospital, Clinic of Pediatric Endocrinology, Diyarbakır, \\ Turkey \\ ${ }^{5}$ Çukurova University Faculty of Medicine, Department of Pediatric Endocrinology, Adana, Turkey \\ 6istanbul University-Cerrahpaşa, Cerrahpaşa Faculty of Medicine, Department of Pediatric Endocrinology, Istanbul, Turkey \\ 7 University of Health Sciences Turkey, Konya Training and Research Hospital, Clinic of Pediatric Endocrinology, Konya, Turkey
}

\section{What is already known on this topic?}

Severely virilized patients with 46,XX congenital adrenal hyperplasia (CAH) can be raised as males but the number of these patients is small and data on their follow-up is lacking.

\section{What this study adds?}

Most $(65.9 \%)$ of the 46,XX CAH cases raised male were diagnosed after two years of age. In 46,XX CAH cases, hysterectomy and bilateral salpingoopherectomy, genital corrective surgeries and testicular prosthesis operations were performed in a very wide age range.

\section{Abstract}

Objective: To retrospectively evaluate the follow-up data in patients with 46,XX congenital adrenal hyperplasia (CAH) who were raised male.

Methods: A national database was created. The data of patients were asked to be recorded in the data form.

Results: The median (range) age of diagnosis was three (0.1-18.3) years in 44 patients. Twenty nine cases were diagnosed after the age of two years. Most $(95.4 \%)$ cases were stage $4-5$ virilized. Hysterectomy and bilateral salpingoopherectomy, at a median age of 7.25 (2.4-25.3) years, was performed in 35 cases. Testicular prostheses were placed in 11 (25\%) cases at a median age of 11.2 (2.8-17) years. The median final height was $149.2(132.8-172) \mathrm{cms}$ in 38 patients, including simple virilizing $(\mathrm{n}=18)$, salt-wasting $(\mathrm{n}=6)$, and 11-beta hydroxylase $(n=12)$. Of the 16 patients above the age of eighteen, university education was completed in $25 \%$.

Conclusion: It was seen that most (65.9\%) of the 46,XX CAH cases raised male were diagnosed after two years of age. In these cases, hysterectomy and bilateral salpingoopherectomy, genital corrective surgeries and testicular prosthesis operations were performed in a very wide age rage.

Keywords: 46,XX, congenital adrenal hyperplasia, final height 


\section{Introduction}

According to consensus guidelines published in 2006, severe virilization during the neonatal period should not be considered a criterion for male sex determination, and 46,XX congenital adrenal hyperplasia ( $\mathrm{CAH}$ ) cases should be raised as females (1). This recommendation is supported by the fact that most of these patients identify as females and moreover, they retain their sexual and reproductive function (2). However, the age at diagnosis, age of initiation of glucocorticoid treatment, and degree of virilization were not considered. Some studies that considered these factors proposed that severely virilized patients with 46,XX CAH may be raised as males $(3,4,5)$. Gender determination at birth and appropriate family and social support may be important in shaping sexual identity $(5,6)$. Lee et al (4) suggested that the social and cultural environment is important to the gender identity of severely virilized 46,XX CAH patients. Gender dissatisfaction in adolescence and adulthood is high among patients with brain virilization caused by perinatal androgen exposure, particularly in girls with a delayed $\mathrm{CAH}$ diagnosis (7). Daae et al (8) performed a systematic review of the literature, investigating sexual orientation in individuals with $\mathrm{CAH}$. This recently published review included 30 studies investigating sexual orientation in patients with $\mathrm{CAH}$ assigned female at birth $(46, \mathrm{XX})(\mathrm{n}=927)$ or assigned male at birth $(46, \mathrm{XY}$ and $46, \mathrm{XX})(\mathrm{n}=274)$. A majority of assigned females with $\mathrm{CAH}$ self-identified (defined themselves) as heterosexual, but figures varied widely across studies (40$100 \%$ ). Results indicate that fewer assigned females reported homosexual (3-20\%) or bisexual orientation (3.4-37\%). The rates of non-heterosexual orientation were higher in assigned females with $\mathrm{CAH}$ than controls, whereas no individuals with $\mathrm{CAH}$ assigned male (46,XY or $46, \mathrm{XX})$ expressed any nonheterosexual orientation.

Patients with $\mathrm{CAH}$ are often diagnosed late in countries without a newborn screening program for the disorder. Such patients tend to be raised as males by their families. Even virilized $\mathrm{CAH}$ patients diagnosed early may be raised as males in male-dominant societies. Follow-up data on 46,XX $\mathrm{CAH}$ patients raised as males are insufficient. Experiences in 46,XX CAH patients raised as males are mostly in the form of case reports. In this study, it was planned to evaluate 46,XX CAH cases followed up with this diagnosis in our country. Therefore, this study aimed to create a national database of 46,XX CAH patients including retrospectively collected diagnostic and follow-up data.

\section{Methods}

This study included 46, XX patients with $\mathrm{CAH}$ raised as males (21 hydroxylase and 11 beta hydroxylase-deficient
$\mathrm{CAH}$ patients; analyzed as a single group given their similar clinical characteristics). The diagnosis of $\mathrm{CAH}$ was made based on medical history, physical examination, and cytogenetic and hormonal analyses. The diagnosis of salt-wasting 21 hydroxylase deficiency was made on the basis of findings of salt-wasting, ambiguous genitalia and elevated 17-hydroxyprogesterone levels. The diagnosis of simple virilizing 21 hydroxylase deficiency was made on the basis of findings of ambiguous genitalia and elevated 17-hydroxyprogesterone levels without salt wasting. The diagnosis of 11 beta hydroxylase deficiency was made on the basis of findings of ambiguous genitalia and elevated 11-deoxycortisol levels. Cytogenetic studies confirmed the karyotype to be 46,XX. Patients with a history of additional chronic systemic disease or chronic drug use for reasons other than $\mathrm{CAH}$ were excluded from the study.

National-scale projects in Turkey, such as the current study, are supported by the Pediatric Endocrinology and Diabetes Association. After receiving approval from the Pediatric Endocrinology and Diabetes Association, the details of the project, including the start and end dates for data collection (July 11, 2018 and January 31, 2019, respectively), were sent to all participating pediatric endocrinology clinics via e-mail. The clinics were also provided with access to online data entry forms (cedd.saglik-network.org site). The data form (Table 1) is provided in the supplementary material. Adult endocrinology clinics were not invited to take part in the study.

Diagnostic and follow-up data were obtained retrospectively from patient records. The requirement for informed consent was waived due to the retrospective nature of the study.

\begin{tabular}{l}
\hline Table 1. Data form \\
\hline Age of diagnosis \\
Height/height sds at diagnosis \\
Weight/weight sds at diagnosis \\
Virilization Prader stage at diagnosis \\
Steroid treatment type at diagnosis \\
Age of hysterectomy and bilateral salpingoopherectomy \\
Age of first genital corrective surgery \\
Number of genital corrective surgeries \\
Testicular prosthesis placement age \\
Steroid treatment compliance \\
Testosterone treatment start age \\
Testosterone treatment compliance \\
The presence of breast development \\
Age of last follow-up \\
Duration of follow-up \\
Final height \\
Education status \\
Working condition
\end{tabular}


The genital virilization levels of the patients were evaluated by pediatric endocrinologists at the time of diagnosis and staged according to the Prader classification (9).

This study was approved by Zekai Tahir Burak Women Health Training and Research Hospital Clinical Research Ethics Committee (approval number: 15/2018, date: 06.03.2018).

\section{Statistical Analysis}

Statistical analysis was done using Statistical Package for the Social Sciences, version 22 (IBM Inc., Armonk, NY, USA). For evaluation of the normality distribution of the data, the Shapiro-Wilk test was used. The statistical significance was investigated using t-test for numerical variables, MannWhitney $U$ test for non-normal distributions, cross table, Pearson chi-square test and Fisher's exact test for categorical variables. A $p<0.05$ was considered statistically significant.

\section{Results}

\section{Total Number and Distribution of Patients}

Data for 44 patients from seven Pediatric Endocrinology Centers were analyzed. In seven Pediatric Endocrinology Centers, the total number of patients with $46, \mathrm{XX}$ CAH was 439. Of these $439,44(10 \%)$ were raised as male. Of the $44 \mathrm{CAH}$ cases, 30 (68.1\%) were CYP21A2-deficient CAH and $14(31.8 \%)$ were CYP11B1-deficient. Of the CYP21A2 deficient CAH cases, 10 (33.3\%) were of the salt-wasting type and the remainder were of the simple virilizing type. The characteristics and clinical findings of the patients at diagnosis and the final follow-up are given in Table 2.

\section{Age and Virilization Stage at Diagnosis}

The median (range) age at diagnosis was $3(0.1-18.3)$ years. Fifteen patients $(34 \%)$ were diagnosed at $<2$ years of age, while $29(65.9 \%)$ were diagnosed at $>2$ years of age. Eight patients were diagnosed during the neonatal period. Only two cases (4.6\%) were Prader stage 3 (one case early diagnosis 11 beta hydroxylase deficiency, one case late diagnosis simple virilizing 21 hydroxylase deficiency); the remaining 42 cases $(95.4 \%)$ were stage $4(n=13)$ or 5 $(n=29)$.

\section{Surgeries}

Hysterectomy and bilateral salpingoopherectomy was performed in 34 cases, at a median age of 7.25 (2.4-25.3) years. Early diagnosed cases were operated at a median of 7.8 (3.5-12) years while late diagnosed cases were operated at 7.8 (2.4-25.4) years. In six cases (17\%), these procedures were performed at $\leq 3.5$ years of age.
Table 2. Clinical follow-up characteristics of 46,XX congenital adrenal hyperplasia patients raised male

Clinical characteristics

Age of diagnosis, median (range) in years

Age of last follow-up mean \pm SD (range) in years

Duration of follow-up mean \pm SD (range) in years

$3(0.1-18.3)$

$14.9 \pm 5.7(1-24.9)$

$10 \pm 6.1(0.1-24)$

Newborn $(\mathrm{n}=8)$

$<2$ years $(n=7)$

Distribution of patients by age of diagnosis

Pre-schooler $(n=18)$

School-aged $(n=5)$

Adolescents $(n=5)$

Adult ( $\geq 18$ years) $(n=1)$

Stage $3(n=2)(4.5 \%)$

Virilization Prader stage in diagnosis Stage $4(n=13)(29.5 \%)$

Stage $5(n=29)(65.9 \%)$

Median (range) age of hysterectomy 7.25 (2.4-25.3) and bilateral salpingoopherectomy (years) $(n=34)$

Number of patients who had more than one operation

Median (range) testicular prosthesis placement age $(n=11)$ (years)

Steroid treatment compliance

$n=13(38.2 \%)$

$14(2.8-17)$

Good $(n=19)(42.2 \%)$

Poor $(n=26)(57.7 \%)$

Testosterone treatment start age, mean \pm SD (range) (years) $(n=21)$

$14 \pm 1.85(10-17)$

Testosterone treatment compliance

Good ( $\mathrm{n}=18)(85.7 \%)$

Poor $(n=3)(14.2 \%)$

Median

Final height $(\mathrm{cm})(\mathrm{n}=38)$

$149.2(132.8-172)$

Genital reconstructive surgery was performed in 12 (27.2\%) patients; two of these patients were Prader stage 3, and 10 were Prader stage 4 . Genital reconstructive surgery was performed once in four cases, twice in six cases, and four times in two cases. The first genital corrective surgery was performed at the a median of 8.5 (2-14.5) years.

A testicular prosthesis was placed in 11 (25\%) cases. The testicular prosthesis was replaced at a median age of 11.2 years (2.8-17) years which varied by period of diagnosis: late diagnosis 15.5 (14-17) years and early diagnosed cases 9.8 (2.8-14) years. Breast development occurred in 12 cases with bilateral oophorectomy, four of whom underwent a mastectomy. Eight of the patients did not consent to surgery.

\section{Treatment}

All patients were started on glucocorticoid replacement treatment at the time of diagnosis which consisted of 
hydrocortisone and hydrocortisone-equivalent steroid treatment in 30 and 14 patients, respectively. However, steroid treatment compliance was low, at $56.8 \%$.

Testosterone treatment was started in 21 cases. The mean age at initiation of testosterone treatment was $14 \pm 1.85$ years, with a range of 10-17 years, and the mean duration of the treatment was $4.76 \pm 2.63$ years. Testosterone depot forms were started at a dose of $50 \mathrm{mg} / 4$ weeks. The dose was increased by $50 \mathrm{mg}$ over six months, and the full dose of $250 \mathrm{mg}$ was reached in two years. Only three cases (14.2\%) were unsuitable for testosterone treatment. Testosterone treatment was started in 13 patients at the age of $>14$ years. The age of initiation of testosterone treatment in eight patients was between the ages of 10-14 years. Testosterone treatment was not started in eight cases despite an age $>14$ years.

\section{Duration of Follow-up and Final Height}

The median age at the last examination was 15.3 years and the median follow-up duration was $10.7(0.1-24)$ years. A total of $28(63.6 \%)$ patients were aged $>14$ years. Thirty-eight patients (18 patients with simple virilizing 21 hydroxylase deficiency, six patients with salt wasting 21 hydroxylase deficiency, 14 patients with 11 beta hydroxylase deficiency) reached their final height during the follow-up. The median final height was 149.2 (range: 132.8-172) $\mathrm{cm}$.

\section{Education and Job}

Of the 16 patients aged $>18$ years, two were primary school graduates, four were high school students, six were high school graduates, two were university students, and two were university graduates. University education was completed by $25 \%$ of the patients.

Regarding employment type, one patient was a shepherd, one had an assembly job, one was an office apprentice, one was an "asphalt worker" and one was a chemical engineer. Only 5 of the 10 adult patients (two primary school graduates, six high school graduates, and two university graduates) had a job with medical insurance.

\section{Discussion}

This study is the largest case series of $46, \mathrm{XX}$ CAH patients raised as males reported to date. Although it has been recommended by physicians that patients diagnosed as newborns or during early infancy be raised as girls, families may desire to raise their child as a boy in male-dominated societies. In our study, the majority of the 46,XX CAH patients raised as males were diagnosed after the age of two years, but approximately one-third were diagnosed at an earlier stage. The upbringing of 46,XX CAH patients diagnosed early and identified as male may depend on the culture of the country of birth. In the literature, the majority of 46,XX CAH patients raised as males were diagnosed late $(4,10,11,12,13)$. Few patients are diagnosed before the age of two years (3). In our cohort, it was recommended that female patients diagnosed at $<2$ years of age be raised as females, particularly those diagnosed during the neonatal period. However, some families insisted on raising their child as a male. Although family preferences and sociocultural factors are important, virilization also plays a role in the decision to raise these patients as males. In studies from countries with different sociocultural contexts, most patients with 46,XX CAH raised as males are Prader stage 4 or $5(3,10,13,14)$. In our study, $95.5 \%$ of the patients were Prader stage 4 or 5 ; only two (4.5\%) were Prader stage 3 . According to the literature, few Prader stage 2-3 patients are raised as males, similar to our study $(12,15,16)$.

According to the current consensus, surgeries leading to irreversible infertility should not be performed in patients with sex development disorders until their sexual identity is clear (17). However, hysterectomy and bilateral salpingoopherectomy are almost always performed during childhood in 46 ,XX CAH patients $(3,13,14,15)$. In our series, the median age of patients who underwent hysterectomy and bilateral salpingoopherectomy was 7.25 but varied widely from 2.4 to 25.3 years. In eight $(22.8 \%)$ patients, hysterectomy and bilateral salpingoopherectomy were performed at the age of $\leq 3.5$ years. These surgeries were performed at the age of 25.5 years in a patient diagnosed with 46,XX CAH when he was 18 years and four months old. This patient had not presented to the endocrine department prior to being diagnosed with 46,XX CAH. He was diagnosed with an undescended testicle at the ages of five and eight years, but no further examinations were performed. In 33 other patients, hysterectomy and bilateral salpingoopherectomy were performed before the age of 15 years. About $68 \%$ of the cohort were aged $<10$ years, which is the average age of onset of puberty, and the surgery was performed without a full assessment of sexual identity. Hysterectomy and bilateral salpingoopherectomy operations should be performed only after the sexual identity of the child becomes clear, that is when the individual can adequately express their desire in that respect.

A testicular prosthesis was placed in 11 patients (25\%) in our series and the median (range) age of implantation was $11.2(2.8-17)$ years. Similar to the literature, the rate of testicular prosthesis placement was low and the age at placement varied $(3,13,14,15)$. There is no standard age for testicular prosthesis placement, and no recommendations 
regarding changing the testicular prosthesis of a patient to one of a different size $(3,13,14.15)$. Therefore, this is left to the discretion of the managing clinicians.

Breast development is particularly obvious during puberty in 46,XX CAH patients raised as males. Breast development may also occur in patients who are unsuitable for steroid treatment and breast surgery may be required in these cases $(10,13)$. In our series, breast development occurred in 12 patients with mastectomy being performed in four of these cases. Hysterectomy and bilateral salpingoopherectomy were performed in 10 of 12 cases with breast development. This suggests that treatment incompatibility may have an etiological role. It should be emphasized, both to the patients and their families, that patients who need a large number of genital corrective operations must comply with treatment to prevent the requirement for an additional mastectomy.

Compliance with testosterone treatment was generally good among our patients. However, steroid compliance was poor and approximately half of the patients were unsuitable for steroid treatment. Without steroid treatment, 46,XX $\mathrm{CAH}$ patients may exhibit increased levels of androgens, potentially making them feel better. However, to avoid the negative effects associated with a lack of steroid treatment (short stature, risk of adrenal crisis at any age), the importance of treatment compliance should be impressed upon patients and their families.

Thirty-eight patients reached their final height during the follow-up. The median final height was $149.2 \mathrm{~cm}$ (range: 132.8-172 cm), which is too short for individuals to continue living as men. In all children with $\mathrm{CAH}$, boys and girls, androgen excess causes accelerated bone maturation and growth and reduces adult height. In these children, hydrocortisone replacement therapy is very challenging: overdosing results in growth inhibition and excessive weight gain, whereas underdosing results in accelerated bone maturation and short adult height (18). A meta-analysis reviewed adult height data until 2008 and confirmed height loss; the mean adult height in salt wasting and simple virilizing patients was -1.38 standard deviation (SD)-score (-1.56 to -1.2) (19). Bretones et al (20) monitored French $\mathrm{CAH}$ children from the pre-screening era and found that patients had a shorter adult height than the general population mean: $-1.2 \mathrm{SD}(156.7 \mathrm{~cm})$ in girls and $-1 \mathrm{SD}$ $(168.8 \mathrm{~cm})$ in boys. In comparison with the general French population, short AH ( $<-2$ SD score) was seen in $24 \%$ of the cohort (22.5\% of girls and $26 \%$ of boys) and presented with a dramatically advanced 8-year bone maturation that strongly influenced the risk of short adult height. Several authors have found a better height outcome in patients who received fludrocortisone (21). A higher pubertal hydrocortisone dose was associated with a slightly higher risk of short adult height. This may be due to the well-known negative effect of excessive glucocorticoid doses on growth $(21,22)$. High hydrocortisone doses may reflect a poorly controlled disease either because of disease severity or secondary to poor compliance to the treatment. The adult heights achieved are actually below the average and $20 \%$ of adult CAH patients have a short adult height (below -2 SD) (20). The final height achieved in patients with $46, \mathrm{XX}$ CAH is very important, particularly if they are to be raised as males, given its psychosocial effects. Woelfle et al (11) reported a patient who attempted suicide due to short stature. Families of 46,XX CAH patients raised as males should be informed that their children will not be fertile, and that they will be short. In these cases, early and long-term growth hormone treatment and aromatase inhibitors may be beneficial (23). If growth hormone treatment is to be used (which should only be for a protracted period), planning should begin at the youngest possible age.

Follow-up of 46,XX CAH cases raised as males is important during adulthood to assess quality of life. Further studies on this subject are needed. Only $25 \%$ of the 16 cases aged $>18$ years in this study received a university education. According to the data of the Statistical Institute in our country, the ratio of faculty or high school graduates to the population was $15.7 \%$. Thus the educational achievement rate of these patients was not lower than the general population.

All patients were followed up in the pediatric endocrine clinic. Clinics facilitating transition to adulthood should be established for 46,XX CAH patients aged $>18$ years raised as males. A multidisciplinary approach should be taken, with follow-up throughout life to assess endocrine function and psychiatric status.

The main strengths of our study were the inclusion of a large number of 46,XX CAH patients raised as males, and the availability of follow-up data. It is important to note that this study included a sample drawn from clinics nationwide, such that the outcomes should be generalizable.

\section{Study Limitations}

A limitation of our study was that some of the patient data were obtained retrospectively. Also, comparing 46,XX $\mathrm{CAH}$ patients raised as females with those raised as males during the same period would have provided more valuable information.

\section{Conclusion}

No guidelines for the care and management of 46,XX CAH patients raised as males are available. The results of our 
study, which is the largest case series of 46,XX CAH patients raised as males conducted to date, can be summarized as follows. The 46,XX CAH patients raised as males were diagnosed late, and included cases of advanced virilization. Surgeries that eliminated the potential for fertility were mostly performed without a full assessment of gender identity. Testicular prosthesis placement rate, and the age at placement, were highly heterogeneous. The onset of testosterone treatment was late, and the rate of treatment was inadequate. Steroid treatment compliance was poor, and the final height of most patients was short for males. We recommend that irreversible surgeries that impair the possibility of fertility should be avoided unless an explicit self-consent is obtained. A consensus should also be sought regarding testicular prostheses, and the importance of steroid hormone treatment compliance to final height should be emphasized to 46,XX CAH patients raised as males. Sexual identity assessments should be performed periodically, and clinics should be established to facilitate the transition to adulthood. Finally, given the importance of sharing experience, adult follow-ups visits should be scheduled.

\section{Ethics}

Ethics Committee Approval: This study was approved by Zekai Tahir Burak Women Health Training and Research Hospital Clinical Research Ethics Committee (approval number: 15/2018, date: 06.03.2018).

Informed Consent: The requirement for informed consent was waived due to the retrospective nature of the study.

Peer-review: Externally peer-reviewed.

\section{Authorship Contributions}

Surgical and Medical Practices: Şenay Savaş-Erdeve, Zehra Aycan, Semra Çetinkaya, Ayşe Pınar Öztürk, Firdevs Baş, Şükran Poyrazoğlu, Feyza Darendeliler, Elif Özsu, Zeynep Şıklar, Meliha Demiral, Edip Unal, Mehmet Nuri Özbek, Fatih Gürbüz, Bilgin Yüksel, Olcay Evliyaoğlu, Nesibe Akyürek, Merih Berberoğlu, Concept/Design: Merih Berberoğlu, Zehra Aycan, Şenay Savaş-Erdeve, Data Collection or Processing: Şenay Savaş-Erdeve, Zehra Aycan, Semra Çetinkaya, Ayşe Pınar Öztürk, Firdevs Baş, Şükran Poyrazoğlu, Feyza Darendeliler, Elif Özsu, Zeynep Şıklar, Meliha Demiral, Edip Unal, Mehmet Nuri Özbek, Fatih Gürbüz, Bilgin Yüksel, Olcay Evliyaoğlu, Nesibe Akyürek, Merih Berberoğlu, Analysis or Interpretation: Merih Berberoğlu, Zehra Aycan, Zeynep Şılar, Şenay Savaş-Erdeve, Literature Search: Şenay Şenay Savaş-Erdeve, Zehra Aycan, Merih Berberoğlu, Writing: Şenay Savaş-Erdeve, Merih Berberoğlu, Zehra Aycan, Zeynep Şıklar.
Conflict of Interest: No conflict of interest was declared by the authors.

Financial Disclosure: The authors declared that this study received no financial support.

\section{References}

1. Hughes IA, Houk C, Ahmed SF, Lee PA. Consensus statement on management of intersex disorders. J Pediatr Urol 2006;2:148-162. Epub 2006 May 23

2. Furtado PS, Moraes F, Lago R, Barros LO, Toralles MB, Barroso U Jr. Gender dysphoria associated with disorders of sex development. Nat Rev Urol 2012;9:620-627. Epub 2012 Oct 9

3. Apóstolos RAC, Canguçu-Campinho AK, Lago R, Costa ACS, Oliveira LMB, Toralles MB, Barroso U Jr. Gender identity and sexual function in 46, XX patients with congenital adrenal hyperplasia raised as males. Arch Sex Behav 2018;47:2491-2496. Epub 2018 Oct 5

4. Lee PA, Houk CP, Husmann DA. Should male gender assignment be considered in the markedly virilized patient with $46, \mathrm{XX}$ and congenital adrenal hyperplasia? J Urol 2010;184:1786-1792. Epub 2010 Aug 21

5. Lee PA, Houk CP. Review of outcome information in 46,XX patients with congenital adrenal hyperplasia assigned/reared male: what does it say about gender assignment? Int J Pediatr Endocrinol 2010;2010:982025. Epub 2010 Dec 21

6. Houk CP, Lee PA. Approach to assigning gender in $46, \mathrm{XX}$ congenital adrenal hyperplasia with male external genitalia: replacing dogmatism with pragmatism. J Clin Endocrinol Metab 2010;95:4501-4508.

7. Dessens AB, Slijper FM, Drop SL. Gender dysphoria and gender change in chromosomal females with congenital adrenal hyperplasia. Arch Sex Behav 2005;34:389-397.

8. Daae E, Feragen KB, Waehre A, Nermoen I, Falhammar H. Sexual orientation in individuals with congenital adrenal hyperplasia: A systematic review. Front Behav Neurosci 2020;14:38.

9. Prader A. Der Genitalbefund beim Pseudohermaphroditismus femininus des kongenitalen adrenogenitalen Syndroms; Morphologie, Häufigkeit, Entwicklung und Vererbung der verschiedenen Genitalformen [Genital findings in the female pseudo-hermaphroditism of the congenital adrenogenital syndrome; morphology, frequency, development and heredity of the different genital forms]. Helv Paediatr Acta 1954;9:231. 248.

10. Sharma S, Gupta DK. Male genitoplasty for 46 , XX congenital adrenal hyperplasia patients presenting late and reared as males. Indian J Endocrinol Metab 2012;16:935-938.

11. Woelfle J, Hoepffner W, Sippell WG, Brämswig JH, Heidemann P, Deiss D, Bökenkamp A, Roth C, Irle U, Wollmann HA, Zachmann M, Kubini K, Albers N. Complete virilization in congenital adrenal hyperplasia: Clinical course, medical management and disease-related complications. Clin Endocrinol (Oxf) 2002;56:231-238.

12. Chowdhury TK, Laila K, Hutson JM, Banu T. Male gender identity in children with 46, XX DSD with congenital adrenal hyperplasia after delayed presentation in mid-childhood. J Pediatr Surg 2015;50:20602062. Epub 2015 Aug 28

13. Bin-Abbas B, Al-Humaida D, Al-Sagheir A, Qasem E, Almohanna M, Alzahrani AS. Divergent gender identity in three siblings with 46, XX karyotype and severely virilizing congenital adrenal hyperplasia caused by a novel CYP11B1 mutation. Endocr Pract 2014;20:191-197.

14. Dasgupta R, Schnitzer JJ, Hendren WH, Donahoe PK. Congenital adrenal hyperplasia: Surgical considerations required to repair a 46, XX patient raised as a boy. J Pediatr Surg 2003;38:1269-1273. 
15. Khattab A, Yau M, Qamar A, Gangishetti P, Barhen A, Al-Malki S, Mistry $\mathrm{H}$, Anthony W, Toralles MB, New MI. Long term outcomes in 46, XX adult patients with congenital adrenal hyperplasia reared as males. J Steroid Biochem Mol Biol 2017;165:12-17. Epub 2016 Apr 25

16. Gürbüz F, Alkan M, Çelik G, Bişgin A, Çekin N, Ünal İ, Topaloğlu AK, Zorludemir Ü, AvCl A, Yüksel B. Gender identity and assignment recommendations in disorders of sex development patients: 20 years'experience and challenges. J Clin Res Pediatr Endocrinol 2020;12:347-357. Epub 2020 Mar 26

17. Çetinkaya M, Özen S, Uslu S, Gönç N, Acunas B, Akıncı A, Satar M, Berberoğlu M. Diagnostic and therapeutic approach in newborns with ambiguous genital with disorder of sex development: consensus report of Turkish Neonatal and Pediatric Endocrinology and Diabetes Societies. Turk Pediatri Ars 2018;53(Suppl 1):198-208.

18. Stikkelbroeck NM, Van't Hof-Grootenboer BA, Hermus AR, Otten BJ, Van't Hof MA. Growth inhibition by glucocorticoid treatment in salt wasting 21-hydroxylase deficiency in early infancy and (pre) puberty. J Clin Endocrinol Metab 2003;88:3525-3530.

19. Muthusamy K, Elamin MB, Smushkin G, Murad MH, Lampropulos JF, Elamin KB, Abu Elnour NO, Gallegos-Orozco JF, Fatourechi MM, Agrwal N, Lane MA, Albuquerque FN, Erwin PJ, Montori VM. Clinical review: adult height in patients with congenital adrenal hyperplasia: a systematic review and metaanalysis. J Clin Endocrinol Metab 2010;95:4161-4172

20. Bretones P, Riche B, Pichot E, David M, Roy P, Tardy V, Kassai B, Gaillard S, Bernoux D, Morel Y, Chatelain P, Nicolino M, Cornu C; French Collaborative CAH Growth Study Group. Growth curves for congenital adrenal hyperplasia from a national retrospective cohort. J Pediatr Endocrinol Metab 2016;29:1379-1388.

21. Han TS, Conway GS, Willis DS, Krone N, Rees DA, Stimson RH, Arlt W, Walker BR, Ross RJ; United Kingdom Congenital Adrenal Hyperplasia Adult Study Executive (CaHASE). Relationship between final height and health outcomes in adults with congenital adrenal hyperplasia: United Kingdom congenital adrenal hyperplasia adult study executive (CaHASE). J Clin Endocrinol Metab 2014;99:1547-1555. Epub 2014 May 30

22. Bonfig W, Bechtold S, Schmidt H, Knorr D, Schwarz HP. Reduced final height outcome in congenital adrenal hyperplasia under prednisone treatment: deceleration of growth velocity during puberty. J Clin Endocrinol Metab 2007;92:1635-1639. Epub 2007 Feb 13

23. Javed A, Lteif A, Kumar S. Update on treatment strategies for optimization of final adult height in children with congenital adrenal hyperplasia. Pediatr Endocrinol Rev 2012;10:164-173. 